\title{
Psicanálise Baseada em Evidências?
}

\author{
LIANA ALBERNAZ DE MELO BASTOS ${ }^{1}$
}

\section{RESUMO}

\begin{abstract}
A partir da discussão sobre a eficácia da psicanálise, a autora considera necessário o diálogo com as neurociências e a psicofarmacologia. Aponta como o critério de eficácia, entendido pela medicina baseada em evidências, apaga a dimensão da narratividade e, conseqüentemente, da subjetividade. Apresenta uma vinheta de um atendimento emergencial no Hospital Universitário Clementino Fraga Filho como possibilidade de se manter a escuta psicanalítica no atendimento psiquiátrico.
\end{abstract}

Palavras-chave: Subjetividade, narratividade, eficácia. 


\section{A Psicanálise Pode Ser Eficaz?}

Em entrevista recente, Elisabeth Roudinesco considerou a psicanálise uma teoria da liberdade, situada entre a filosofia e a ciência, voltando-se, muitas vezes, contra a ciência quando esta assume um discurso totalizante com a pretensão de se fundar como religião ou dogma. Esse lugar crítico da psicanálise tem despertado violentas reações, que se traduzem em acusações de ineficácia. "A diferença entre hoje e o início do século é que, naquela época, o antifreudismo era moral, acusava-se a psicanálise de perverter cabeças e hoje acusam-na de não ser eficaz" (O Globo, 12/2/2000, Caderno Prosa \& Verso, p. 6).

A eficácia terapêutica tornou-se um critério fundamental numa cultura biotecnicista e pragmática. A eficácia de uma terapêutica é medida pela sua capacidade em fazer o sujeito, o mais prontamente possível, retornar à normalidade para o desempenho de suas funções sociais. A discussão da normalidade como um critério de saúde já foi exaustivamente criticada por Canguilhem (1978) e, entre nós, por Coelho \& Almeida F (1999) e Sayd (1999).

Por outro lado, a avaliação do desempenho das funções sociais é objetivamente mensurada por parâmetros que são impregnados de uma dada visão ideológica. A eficácia terapêutica trata-se, assim, não nos iludamos, de um critério determinado pelas leis do mercado. Ainda que a psicanálise pretenda escapar desse critério, tais leis também vigoram no campo psicanalítico. A sobrevivência da psicanálise, segundo Peter Fonagy (1999), depende desse fator. A produção intelectual e o desenvolvimento da teoria são sustentados pelo trabalho clínico psicanalítico e este depende da indicação de pacientes, seja por profissionais da área de saúde, seja pelos próprios pacientes.

Em alguns países - e, em nosso meio, alguns convênios - companhias de seguro cobrem os custos dos tratamentos psicanalíticos desde que estes apresentem resultados.

“Assim, as condições da prática dependem da cultura profissional e do valor cultural que se outorga à psicanálise e à psicoterapia. Estes fatores estão determinados por condições sociais (...). Uma sociedade progressivamente pragmática, que outorga um valor implícito ao acesso instantâneo e igualitário a soluções rápidas para os problemas de saúde mental, cria uma cultura profissional que oculta uma ideologia da medicina baseada em evidências para 
lidar com o problema da distribuição desigual dos recursos destinados ao cuidado da saúde" (Fonagy, 1999, p. 25).

Mas, continua ele,

"a medição atual do mal-estar psicológico é reducionista (...) Como se pode quantificar 'uma vida ética' ou um 'sentido de existência'? Chamar uma medida de 'qualidade de vida' não significa que os números obtidos reflitam essa complexa construção. Sem embargo, vivemos numa cultura em que uma forma de tratamento que não conta com uma "evidência sólida" só pode ser vista como "carente de valor"” (Fonagy, 1999, p. 25).

O reducionismo quantitativo que se faz da avaliação do mal-estar psicológico fica mascarado pela expressão "qualidade de vida". Usada como critério de eficácia, a qualidade de vida não tem metodologia adequada que permita considerar seus aspectos qualitativos. Os múltiplos sentidos da vida de um sujeito que emprestam a ela qualidade só podem ser compreendidos dentro das singularidades das experiências. Não há mensuração possível que torne evidente essa qualidade. A psicanálise, ao tratar das subjetividades, tem na metodologia qualitativa sua referência, tornando-se, assim, dentro dos critérios tidos como de eficácia terapêutica, carente de valor.

A essa "carência de valor" da psicanálise somam-se muitas outras críticas. A psicanálise, segundo alguns, não seria mais atual na medida em que os problemas sobre os quais ela se debruçou - e que fundamentam seu edifício teórico, tais como a sexualidade infantil e o recalque - estariam vinculados historicamente à moral vitoriana do século XIX. A mudança do perfil clínico do paciente psicanalítico, hoje predominantemente borderline, e as dificuldades narcísicas que são o arroz-com-feijão da prática analítica atual confirmariam a ultrapassagem histórica da teoria e da técnica freudianas. A insistência dos psicanalistas em se manterem fiéis ao legado freudiano adviria, nesta perspectiva, de um desconhecimento, por parte desses profissionais, dos avanços científicos da neurobiologia e dos novos recursos psicofarmacológicos.

Críticas merecem ser ouvidas. Estimulam o nosso pensamento. Fazem-nos discutir as mudanças, as repercussões destas na teoria e na prática psicanalíticas e a atualidade das contribuições da psicanálise para a cultura. É preciso que os analistas saiam de suas torres de marfim bastante estilhaçadas pelo esvaziamento clínico -, que nada mais são do que um anteparo arrogante contra o diálogo, muitas vezes difícil, com 
outras áreas do conhecimento.

Isso, contudo, não se resolve com uma adesão rápida para tornar palatável aquilo que nos incomoda. Há que se ter, nessa aproximação, cuidado e respeito na demarcação das diferenças, sem conclusões reducionistas. Neurocientistas são extremamente cautelosos ao fazerem correlações, por exemplo, entre achados fisiológicos e humor, como se pode perceber em Sherwin (1997). Correlacionando o efeito do estrogênio sobre o humor, diz ela:

"São três os mecanismos para aumentar a biodisponibilidade de neurotransmissores. (...). Esses três mecanismos de ação do estrogênio afetarão o humor na medida em que a depressão é, em grande parte, uma doença de déficit de serotonina. Deve-se, então, considerar a hipótese de que a diminuição do estrogênio esteja relacionada com as alterações do humor freqüentes na menopausa" (Sherwin, 1997, p. S25. Grifos nossos).

O diálogo com a neurobiologia tem sido buscado por alguns analistas. Embora extremamente instigante, corre-se o risco de uma transposição e extrapolação apressada das novas descobertas para o campo psicanalítico, numa simplificação tanto da neurobiologia quanto da psicanálise, confundindo-se seus objetos. O objeto da psicanálise, o inconsciente, demanda uma mente corporificada (Bastos, 2000) mas não se confunde com os fenômenos mentais que interessam às neurociências. Acresça-se a isto que o campo da neurociência não é homogêneo. Há nele diferentes visões, que vão desde um materialismo reducionista (como Dennett, por exemplo), passando por um naturalismo biológico (Searle), até um dualismo de difícil sustentação (Penrose). A integração cérebro-corpo não é, dentre eles, consenso. Menos ainda a equivalência cérebro-mente. A questão da linguagem, como sintaxe e como semântica, também perpassa a discussão. $O$ verbal e o não-verbal não são entendidos da mesma forma. Corpo e linguagem nem sempre vêm juntos (Bastos, 2000).

Urrego, psiquiatra e psicanalista colombiano, considera que as descobertas da neurobiologia não são nem uma confirmação nem um desmentido das teorias psicanalíticas. "Simplesmente não se situam no mesmo nível e não creio equivocar-me ao afirmar que também não estão na contramão" (Urrego, 1999, p. 3).

Considera especulativas afirmações, como as de Pally (1997, p. 1.023), de que "se a análise melhora o funcionamento cortical e a plasticidade cortical, pode modular as respostas emocionais profundamente gravadas". É 
preciso, segundo ele, estar atento a que determinados conceitos, como emoções, não são tomados da mesma forma pela psicanálise e pela neurobiologia. Acrescentaríamos, ainda: a subjetividade não é redutível a circuitos neuronais. Por mais complexos que esses sejam, circuitos neuronais e subjetividades não se equivalem.

Alain Prochianz (apud Roudinesco, 2000, p. 32) neurobiologista francês, afirma a pertinência dos campos da neurobiologia, da genética e da psicanálise, não vendo exclusão dentre eles:

"Se os genes definem nossa pertença à espécie e nossa presença física, eles não são os únicos a determinar nossa personalidade de seres pensantes. $\mathrm{O}$ cérebro não é um computador cuja codificação seja ditada pelo aparelho genético."

O inconsciente, no sentido freudiano, continua a ser, segundo Edelman, neurobiologista americano e Prêmio Nobel de Medicina, uma noção indispensável para a compreensão científica da vida mental.

A memória, tema caro tanto às pesquisas neurobiológicas atuais quanto à psicanálise, mostra-se como um exemplo privilegiado das diferenças de abordagens e de objetos e da não-superposição desses dois campos. Os achados neurobiológicos sobre a memória implícita ou não-declarativa (particularmente em relação aos componentes afetivos desta última) não permitem estabelecer uma correlação explicativa com o recalcamento, como lembra Laplanche (1999). Não devemos confundir o recalcamento simplesmente com um caso particular de memória, tomando a lembrança inconsciente como sendo apenas uma lembrança mais profunda do que a pré-consciente. Não se pode fazer uma transposição mecânica do conceito do recalcado.

$\mathrm{O}$ entendimento da equivalência da memória ao recalcado deriva de uma das primeiras hipóteses que Freud fez para o recalque: as representações das quais o sujeito não quereria ou não poderia tomar consciência seriam recalcadas, tornando-se inconscientes. (Lembremo-nos de que o problema, para Freud, nos seus primeiros escritos $(1893,1895)$, era a oposição entre os pólos da memória e da percepção). Nesta hipótese, que Laplanche chama de funcionalista, a representação de um acontecimento - isto é, seu traço mnêmico - é que seria o recalcado. O recalcamento seria, então, a colocação em memória de uma lembrança. Essa hipótese buscou dar conta da gênese do recalcado.

Porém Freud elaborou, em 1915, outra hipótese, tópica, para o recalcamento: a da dupla inscrição. Nesta, as inscrições inconscientes (as 
representações-coisa) e pré-conscientes/conscientes (as representações-palavras) coexistem mas são distintas, operando de modos diversos de funcionamento (primário e secundário, respectivamente), não se reduzindo umas às outras. O trabalho clínico revela que a "tomada de consciência" não abole a inscrição inconsciente. Realizado o recalcamento, a inscrição inconsciente (representação-coisa) mostra sua natureza diferente de uma simples lembrança. Com essa hipótese, Freud buscou explicar não a gênese, mas o retorno do recalcado.

Vale ainda lembrar que a noção de trauma que, em 1895 ("Projeto para uma psicologia científica") foi correlacionada por Freud com a memória, posteriormente foi modificada ("Além do princípio do prazer", 1920), passando a ser da ordem da não-inscrição psíquica, registro da pulsão de morte. Os sonhos de repetição das neuroses traumáticas e a compulsão à repetição na transferência daquilo que é da ordem do horror passaram a constituir o trauma. A insistência do traumático, que se expressa pela angústia, visa à tentativa de inscrição psíquica de busca de um sentido para o disruptivo. $\mathrm{O}$ trauma se descolou, desse modo, da memória. As desordens subjetivas não são redutíveis a traços visíveis na memória.

O reducionismo que perpassa uma boa parte da pesquisa neurobiológica, notadamente a americana, tem feito do trauma, como traço vísivel na memória, um estandarte na sua postura antifreudiana. Em verdade, o que se passa é que o trauma, nessa abordagem, é tomado como Freud o fez na sua primeira abordagem (1895), pré-psicanalítica, anterior à descoberta do inconsciente e da sexualidade infantil (estruturante da subjetividade - o corpo incluído - construída a partir das experiências afetivas): como uma "alocação" na memória da lembrança de um abuso sexual.

Assim, a verdadeira epidemia da "síndrome de personalidade múltipla" que assola a sociedade americana se apoiaria neste enfoque, como bem ilustra o entendimento de Rosenfield (apud Searle, 1998) dessa síndrome. Sustentada numa nosologia que baniu a histeria e a psicose, substituindo-as pela noção imprecisa de distúrbio ou desordem, a histeria ficou reduzida a um distúrbio dissociativo, e a esquizofrenia a uma alteração do curso de pensamento (segundo o Manual diagnóstico e estatístico dos distúrbios mentais - DSM IV). Não é de espantar, portanto, o aparecimento de tantos casos "novos" de distúrbios dissociativos. A psiquiatria, ao desconhecer os conceitos de inconsciente, de recalque, da sexualidade infantil e do trauma como da ordem da não-inscrição psíquica, tudo reduz ao circuito percepção (consciência)-memória (pré-consciência). 
Não se pode esquecer, ainda, que a dimensão que o abuso sexual tomou na sociedade americana revela, por um lado, a ideologia moralista que trata a sexualidade como prática sexual pecaminosa e, por outro, o cientificismo reducionista que desconsidera a constituição subjetivadora e estruturante do corpo erógeno (Bastos, 1998).

A sexualidade reduzida ao sexo deixa de ser uma mola viva das relações humanas e da imaginação criadora. Sai Freud e entra Calvino. Esse retorno histórico traz, do ponto de vista social, conseqüências curiosas: o sexo tornase onipresente na sociedade americana. Os pediatras não examinam as partes genitais das crianças (pede-se aos pais que o façam como se estes dominassem técnicas semióticas), nos ambientes de trabalho há rígidas regras do convívio para punir qualquer insinuação de conteúdo sexual, criamse grupos (a exemplo dos Alcoólicos Anôminos) de "praticantes compulsivos de sexo", a conduta adúltera de um presidente é publicamente esmiuçada em detalhes, ao mesmo tempo que o sexo, junto com a fama e o dinheiro, é vendido como - e faz vender - valor de mercado. Será isto qualidade de vida? As múltiplas e complexas dimensões existenciais dos sujeitos - as inconscientes incluídas - banalizam-se nesse achatamento.

Claro está que o conhecimento médico, como produção histórico-social, reflete essa ideologia, que se dissemina mundialmente pela hegemonia americana. A simplificação reducionista da sexualidade ao sexo corresponde à do sujeito a um consumidor racional e consciente. Essa concepção permeia, hoje, a prática médica como um todo (Berg, 1997).

A psiquiatria também aderiu a este modelo. As revisões do Manual DSM de 1952, em 1968 (DSM II), 1980 (DSM III), 1987 (DSM III-R) e 1994 (DSM IV) expurgaram as categorias de neurose, psicose e perversão, abandonando a idéia presente em 1952, de que os distúrbios mentais decorriam da história inconsciente do sujeito, de seu lugar na família e no social somados a causalidades orgânicas. Esse entendimento indicava tratamentos que associavam o uso de psicofármacos às psicoterapias que privilegiavam a fala do paciente (Roudinesco, 2000). O uso dos psicofármacos e o predomínio da concepção cognitivista na psiquiatria atual, consoante o discurso médico hegemônico, expulsaram a subjetividade de cena.

Memória, consciência e percepção (ou cognição) são tratadas na teoria freudiana mas não são esses seus pontos fundamentais. O que a psicanálise traz de revolucionário é a descoberta do Inconsciente, que deslocou o sujeito do pólo da racionalidade, destronando o privilégio da consciência. O Inconsciente não é meramente um "sentido oculto". Sua existência pressupõe a 
elucidação do sintoma conjuntamente com um método no qual a transferência é fundamental. A psicanálise não é, assim, nem uma hermenêutica, nem uma teoria da comunicação, nem uma biologia. Ela tem um lugar original dentre os saberes que tomam o homem como objeto, inserindo-se no conjunto de teorias da subjetividade. Isso não significa que ela deva se encastelar, colocando-se acima ou abaixo dos demais. É necessário o diálogo com outros campos. Os importantes achados da neurociência não devem nos deixar indiferentes, pois nos auxiliam a delimitar com mais clareza o nosso campo.

A neurociência pode nos oferecer o biológico como modelo para podermos, a partir daí, especular, imaginar, construir novos mitos teóricos na psicanálise. Por seu turno, a Psicanálise pode, também,

"convidar a ciência a reconsiderar seus fundamentos epistemológicos, ao abordar o psiquismo, cuja especificidade e características não são comparáveis a nenhum outro campo do saber. A mente não é uma secreção do cérebro. Nem os critérios das ciências naturais nem os das ciências humanas ou da cultura se acomodam aos nossos" (Urrego, 1999, p. 32).

\section{Psiquiatria Baseada em Evidências}

Em entrevista publicada recentemente (Psiquiatria Hoje, 1999, p. 3), o psiquiatra Maurício Lima, professor da Universidade Federal de Pelotas, Rio Grande do Sul, diz:

"Quando se afirma que não existe evidência científica de qualidade que comprove a efetividade da psicanálise no tratamento de transtornos mentais, não significa que tal método seja ineficaz. Simplesmente, constata-se a inexistência de estudos especialmente delineados para testar a eficácia deste e de outros modelos terapêuticos".

O que o entrevistado postula é uma psiquiatria baseada em evidências, "uma inserção da especialidade no modelo médico tradicional". Deste modo, a avaliação da eficácia da psicanálise se fundaria na metodologia científica própria do conhecimento da modernidade utilizada no modelo médico.

A psiquiatria baseada em evidências é a aplicação, nesta especialidade, da medicina baseada em evidências. A medicina baseada em evidências (MBE) é a denominação de um movimento, que emergiu na década de 90 , ligado à epidemiologia clínica anglo-saxônica, que se propunha a estudar as 
eficácias diagnósticas e terapêuticas dos procedimentos utilizados na prática médica. Produto dos domínios tecnobiocientíficos, foi definida, originalmente como o processo de sistematicamente descobrir, avaliar e usar achados de investigações como base para decisões clínicas (Castiel, 1999). A meta apregoada da MBE é procurar diminuir a distância entre o conhecimento científico, teórico e a sua aplicação prática, transformando-o em elemento de apoio às decisões diagnósticas e terapêuticas e em instrumento para uma atuação profissional melhor (Novaes, 1999).

Eficácia, efetividade, eficiência e legitimidade. Estes são os anseios da MBE. O desenvolvimento da informática, tanto no processamento quanto na difusão das informações, permitiu que os resultados das realizações de protocolos de pesquisa multicêntricos, envolvendo um grande número de casos e potencializando as possibilidades de generalização dos resultados obtidos, fossem tomados como padrão-ouro. Esses resultados, padrão-ouro, são obtidos através de ensaios clínicos controlados e servem de eixo de sustentação para o desenvolvimento de guidelines para a boa prática profissional, com legitimidade para serem aceitos como verdadeiros pelos profissionais e constituindo-se em elemento de apoio à decisão diagnóstica e terapêutica. Essa concepção acredita ser possível, por um lado, produzir conhecimentos sólidos sobre a etiologia das doenças e sobre métodos preventivos, diagnósticos e terapêuticos que precisam ser continuamente atualizados e, por outro, modificar, pelo acesso a essas informações, a prática dos médicos num processo de educação continuada (Novaes, 1999).

Sem desconhecer que os estudos da MBE têm sido úteis para denunciar drogas perigosas, exames inúteis e iatrogenias decorrentes de abuso médico, convém, no entanto, estar atento para o intenso debate que a MBE tem provocado no âmbito das ciências da saúde.

Almeida $\mathrm{F}^{\circ}$ (apud Castiel, 1999) chama a atenção para o fato de que a incorporação tecnológica em saúde em nosso meio, tal como se apresenta no movimento MBE, significa uma postura submissa ao imperialismo científico que caracteriza a etapa atual do processo histórico de globalização econômica e cultural, fundando-se na fórmula informação-tecnologia sem considerar o processo de produção do conhecimento. A MBE baseia-se na fórmula informação-tecnologia. Esta fórmula é incompleta, posto que a tecnologia é um dos produtos (mas não o único) de um processo de produção peculiar, denominado ciência, e informação é uma das fases intermediárias desse ciclo produtivo. Para o autor, a MBE se calca no paradigma cartesiano, não sendo assim capaz de dar conta da complexidade do campo 
da intervenção em saúde.

Para Barata (apud Castiel, 1999), a matriz ideológica na qual se apóia a MBE faz transparecer a faceta empírico-lógica das tecnobiociências, mediante mitos vinculados entre si, a saber: a incondicional objetividade do conhecimento científico e sua capacidade de evidenciar "verdades"; a potência do instrumental quantificador probabilístico neste processo; a idéia de progresso irrestrito no desenvolvimento de produtos, técnicas e intervenções; e a forte crença na neutralidade do empreendimento científico cuja premissa maior é a dicotomia sujeito/objeto e, por conseguinte, o controle de ambos, otimizando a objetividade e evitando os "perigos" da subjetividade.

Como aponta Castiel (1999), dentro do programa tecnobiocientífico, médicos não são educados para lidar com a dimensão do sofrimento embutido nas manifestações oriundas de processos de adoecer traduzidos por signos construídos pela semiologia médica e pelas tecnologias diagnósticas e propedêuticas. Os praticantes da biomedicina contemporânea são treinados de um modo cético que tende a minimizar, no momento da intervenção, os fenômenos da chamada subjetividade ou então a tentar controlá-los, tal como essa é dimensionada no interior deste campo: como efeito dito psicofisiológico ou placebo. A dimensão narrativa, fundamental na clínica, é desqualificada, e a medicina modelizada passa a se apresentar como campo de certezas, desconsiderando a singularidade de cada caso.

A dimensão narrativa é própria do humano. Se alguns a entendem como recurso biológico (Dennett, 1991) - e ela efetivamente também o é - a linguagem transcende o organismo. Objeto de discussão de filósofos, biólogos, literatos, psicanalistas etc., a narratividade tem-se constituído em campo de pesquisa e de debate intenso. Foge aos limites deste trabalho mapear as diferentes e muitas vezes antagônicas concepções atuais sobre a linguagem. Interessa-nos aqui pontuar que, para a psicanálise, a linguagem ao ser tomada como talking cure, inaugura sua experiência. Através da narração das histórias de vida, abre-se, no encontro analítico, a possibilidade de interpretação e de construção de múltiplos sentidos para os romances familiares de cada sujeito, criando-se outras possibilidades do existir.

Sendo ser de narração, o sujeito não se equivale, no entanto, tout court, à linguagem - afetos são experimentados prescindindo-se da expressão verbal - mas ela propicia processos de subjetivação por sua dimensão imaginária.

"O efeito imaginário do ouvir-se falar ou escutar-se é a subjetivação, sentido em que se apresenta um interno ao corpo como lugar de origem do som e 
da idéia, e a objetivação; assim, a partir desse interno, constitui-se um externo como objeto de percepção e de conhecimento" (Lemos, 1996, p. 245).

Ao se tomar a linguagem apenas como código que se organiza e é organizado pela lógica identitária, apaga-se sua outra dimensão fundamental, a de língua, viva e plural, que sempre cria novos sentidos, frutos da imaginação radical própria do humano (Castoriadis, 1995). A dimensão de língua viva criadora não permite qualquer abordagem quantitativa. Ela é singular, remetida à história constitutiva de cada sujeito, tendo sua fonte no Inconsciente. Desse modo, toda e qualquer abordagem do humano que desconsidere essa dimensão, ainda que em nome de uma objetividade, torna-se ineficaz. Ora, a linguagem médica, ao tratar a doença como um universal, ao tomar a história do doente como história da doença, necessariamente abole a singularidade narrativa do paciente. Torna-se, no limite, uma medicina de doenças sem doente. No entanto, como retorno do recalcado, os médicos utilizam adjetivos como provável, sugestivo, compatível e indicativo revelando, assim, o campo impreciso de seu trabalho.

A biomedicina, continua Castiel (1999), tem uma incontestável eficácia em termos de salvamento de organismos mas sua idealização impede de vêla como mal preparada para lidar com objetos não passíveis de abordagens empírico-lógicas. Esse modelo acaba por fazê-la criar obstáculos a outros possíveis modos de entendimento do fenômeno humano e de seus adoecimentos. Perdem-se, assim, outras dimensões terapêuticas. É preciso, diz ele, considerar o papel central desempenhado pelas narrativas e pela idéia de inconsciente do corpo, tanto do lado do paciente quanto daquele que procura abordá-lo. É crucial conceber e desempenhar qualquer atividade assistencial da perspectiva das questões relativas à condição humana, na busca de significações para a vida.

Se estas questões são presentes na formação médica, em geral, que dizer da formação psiquiátrica em particular? E qual o papel que a psicanálise pode aí desempenhar?

\section{Decifra-me ou te Devoro: o Sujeito Humano como Enigma}

\footnotetext{
“Às 11 horas da manhã, sou chamada ao Serviço de Emergência do hospital para atender a uma emergência psiquiátrica.
} 
C., uma mulher de 35 anos, funcionária do hospital, muito agitada, chorava, dizendo que sua casa pegara fogo e que todos haviam morrido. Estava acompanhada da irmã e do filho de 15 anos. Aparecera, ao final da tarde anterior, na casa de sua irmã, chorando e repetindo várias vezes que sua casa pegara fogo. Trazia consigo o filho de 6 anos e sua pasta de deveres escolares. Apontando para os trabalhos escolares, dizia ali estarem os documentos da casa. A irmã a acompanhara até sua casa. Tudo em perfeita ordem. O marido de C. informara à cunhada que, ao chegar em casa, encontrara C. botando as roupas para secar no varal. Em seguida, a mulher saíra.

Aos poucos, C. me contou a sua história. Trabalhava há vários anos no hospital. Gostava imensamente de seu trabalho - sorria enquanto me falava - e sentia-se orgulhosa de ser considerada uma excelente funcionária. (Enquanto a atendíamos, sua chefe, sabedora de sua situação, fora até a emergência para vê-la). Conseguira comprar sua casa e montá-la. Tudo que ela tinha era fruto de seu trabalho e de seu esforço. Seu filho de 15 anos, que não era de seu atual marido, a ajudava. Ele estudava à noite e durante o dia trabalhava numa oficina mecânica. Era muito bom filho, segundo ela. Casarase legalmente com o pai de seu filho de 6 anos. Seu marido fazia biscates, pouco contribuindo para o sustento da casa. Também não gostava do rapaz de 15 anos. Perguntei a C. se seu casamento era bom. Respondeu-me que o marido não lhe batia... Disse-lhe que eu achava que não bater nela não era suficiente para fazer dele um bom marido. Começou a chorar. Ele não a ajudava em nada, implicava com o filho mais velho, batia no menor, não era carinhoso. Perguntei-lhe então se não era o casamento que tinha pegado fogo e morrido.

Essa intervenção promoveu uma mudança no discurso de C. Contou, então, que queria se separar do marido mas temia que ele conseguisse judicialmente ficar com metade dos bens. Temia, também, que ele se recusasse a sair da casa e que mandá-lo embora pudesse desencadear sua violência. Dizia não ter a quem recorrer, pois seus pais eram falecidos e seu cunhado (o marido da irmã que a trouxera), que sempre a amparara, morrera no ano anterior. Sugeri a ela que conversássemos sobre suas aflições com seu filho e sua irmã. Esta se dispôs a ir com um filho adulto para ajudar C. quando ela externasse seu propósito de separação. O filho de C., ao ouvi-la, abraçou-a, dizendolhe que mesmo que o marido levasse parte das coisas que eles poderiam, 
juntos, comprar outras. Sugeri-lhe que procurasse o Departamento Jurídico da Associação de Funcionários para que se informasse de seus direitos legais e de seus filhos.

C. me agradeceu e perguntou se já podia ir embora. Quis saber do filho caçula, que ficara na casa da irmã aos cuidados de uma sobrinha, preocupouse com o dia de trabalho que seu filho mais velho estava perdendo e queria ir embora, pois, à noite, estava escalada para o plantão (Apesar de a chefia tê-la dispensado, ela não queria faltar). C. recebeu alta e não voltou a demandar ajuda psiquiátrica".

A situação acima narrada não se enquadra como relato clínico. A apresentação de um caso obedece a certas regras que não são fortuitas. Tais regras determinam a construção da doença, que implica um modo de se ver a realidade. A formação médica não é apenas um ensino relativo a conhecimentos. O que se visa é a criação de um objeto: o objeto real da prática médica é a doença. Isso não significa que as experiências vividas na relação do médico com seu paciente não sejam consideradas (pelo menos pelos bons clínicos) mas elas não têm interesse médico (Good, 1998).

Penetrar no mundo médico é criar uma maneira codificada de se ver, de se escrever e de se falar. Isso se inicia pela construção de um corpo, o corpo da medicina, fundamentalmente diferente do corpo que experimentamos quotidiamente. $\mathrm{O}$ ensino da anatomia, a porta de entrada do estudante na formação médica, obedece a esse critério. O cadáver é tomado como uma peça a ser estudada através do treinamento do olhar. Há uma metodologia nesse treinamento cujo objetivo é mais do que perceber as diferentes estruturas anatômicas que compõem o corpo humano: o cadáver é tomado como modelo de paciente. O estudante diante do cadáver aprende a "pensar anatomicamente". O esvaziamento da vida que aquele corpo possuiu é condição necessária para a prática anatômica. A dissecção anatômica se faz impossível sem essa condição mas a anatomia não é "desumanizadora" no sentido habitual do termo. Ela é estruturante para a desconstrução do sujeito e reconstrução da pessoa como cadáver (ou como caso clínico).

O trabalho de desconstrução do sujeito e reconstrução da pessoa como paciente se inicia no ciclo pré-clínico pela neutralidade do olhar. Aprender a ver, neutra e tridimensionalmente, é essencial para a biomedicina, melhor dizendo, para a ordem hierárquica da biomedicina, que vai, a partir da superfície, aprofundando-se no processo mórbido até o nível genético. Deste 
modo, a esquizofrenia passa a ser uma desordem genética e, portanto, deve haver uma proteína que a explique. Trata-se, então, de pesquisá-la. A estrutura última é material. Esta visão é ideológica. A idéia associada à biologia molecular e à genética de que o gen tem prioridade ontológica sobre o indivíduo e este sobre a sociedade se casa perfeitamente com o modo individualista, narcísico, que caracteriza a sociedade ocidental contemporânea. O comportamento reside nos genes e as doenças no corpo individual biológico. O olhar torna-se concreto.

Aprendendo a olhar, o estudante é treinado, ao longo da sua formação, no ciclo clínico, a falar e a escrever. Nessa prática formativa, o estudante tem que descrever o paciente como caso clínico, isto é, como documento. A anamnese é o momento desse treinamento. A conversa com o paciente deve ser dirigida de forma a se obter o maior número possível de informações, selecionar as relevantes, abandonar as demais e expô-las com a maior concisão e clareza possíveis.

Todos aqueles que passaram pela formação médica, ou aqueles que, como nós, trabalham com os estudantes nessa fase, sabem das angústias que elaborar uma história clínica levanta. As preocupações em se dizer "o essencial e o relevante", em não deixar de investigar aquilo que interessa (ao enfoque médico, naturalmente), em saber "cortar" a conversa do paciente, em não se deixar "enganar" por aquilo que o paciente diz, em conduzir "corretamente" o interrogatório, mostram o modelo rígido e pré-formado que rege o encontro do futuro médico com o paciente. O poder do médico está na organização desse diálogo e na construção dessa história, para que ele possa determinar um diagnóstico e instituir uma terapêutica da doença. É desse modo que a eficácia médica se dá, qualquer que seja a especialidade, a psiquiátrica incluída (Good, 1998).

A apresentação de caso é o momento público em que essa eficácia é avaliada. Deve-se apresentar o "essencial", isto é, o suficiente para que se possa saber do estado do paciente, das manifestações da doença, dos diagnósticos possíveis e do tratamento apropriado. A súmula psicopatológica é um exemplo acabado desse procedimento. Tudo rápido, sucinto e claro, organizando os eventos de forma cronológica, o início e o desenvolvimento do processo mórbido sem desperdícios de palavras. Estas, por sua vez, são traduções para o jargão médico (a linguagem esotérica da qual o leigo fica excluído) do dito pelo paciente. Pensando estar apresentando a realidade do caso, anulando a dimensão narrativa do paciente, o médico faz uma ficção médica. O paciente, aquele que sofre, é designado como lugar da doença e 
não como agente de sua narrativa. Desse modo, médico e paciente se dessubjetivam no encontro, perdendo cada qual a sua fala própria.

\section{Conclusão}

A literatura psiquiátrica tem tratado, majoritariamente, de funcionamentos neurobiológicos e de pesquisa farmacológica. Ela parece buscar, mais do que qualquer outro campo da medicina, uma validação científica, dentro dos critérios da MBE, e uma eficácia. O assombroso avanço da psicofarmacologia e de métodos altamente sofisticados diagnósticos (PET, SPECT) tem permitido o controle sintomático de patologias graves. Estas, por sua vez, estão sendo nosograficamente redefinidas (TOC, síndrome do pânico), em função da categorização necessária a este processo de produção de uma psiquiatria baseada em evidências que exclui a narratividade e, por conseguinte, a subjetividade de seu campo. O psiquiatra, dentro desse movimento, é um biotecnicista.

Se, por um lado, a produção do conhecimento neurobiológico e os recursos medicamentosos cresceram exponencialmente nos últimos anos, por outro, o entendimento do sofrimento psíquico em sua singularidade tem sido relegado a um plano secundário. A psicanálise, que, há algumas décadas, tinha espaço privilegiado dentro da formação psiquiátrica, vê-se hoje praticamente banida desse campo, quando muito tolerada, desde que se "ajuste" ao modelo da MBE.

Verdade seja dita: não coloquemos a psiquiatria, como um todo, no banco dos réus. Seu braço biotecnocientífico tem lugar e importância. Fundamental é que percebamos que esse braço é tão-somente parte de uma busca de decifração do enigma humano. Ele atende à biologia do corpo mas não esgota as dimensões do sujeito. Urge que outros saberes, e a psicanálise mais do que todos, sejam reinseridos na prática psiquiátrica, revalorizandose a subjetividade. Sem a discussão da interação corpo-mente, com suas dimensões inconscientes e interações recíprocas, sem a narratividade e sem o manejo da transferência, nenhuma atividade assistencial é eficaz. Mais ainda: ela perde a dimensão ética que nasce do debruçar-se sobre o sofrimento humano (Bastos, 1999).

Assim, a eficácia da prática psicanalítica não se pauta pela eficácia da MBE. Não há modelização possível para um saber sobre a singularidade humana. Os psicanalistas não precisam se transformar em cristãos novos, aderindo a uma prática biomédica hegemônica vigente, seja pela vergonha 
(de uma atividade em desprestígio social), pelo medo (do esvaziamento da clínica) ou pelo desconhecimento (pela ignorância da biomedicina). Mais além da remoção de sintomas, a eficácia da Psicanálise é a de, em se suportando o desamparo inerente à condição humana, nos tornar menos impotentes e mais solidários na construção de sentidos para nossa existência.

\section{Referências Bibliográficas}

ALMEIDA $\mathrm{F}^{\mathrm{o}}, \mathrm{N}$.Teoria do conhecimento em saúde: uma crítica prospectiva. Médicos, HC-FMUSP, v. 7, mar./abr., p. 23-29, 1999.

BASTOS, L. A. M. Eu-corpando: o ego e o corpo em Freud. São Paulo: Escuta, 1998.

BASTOS, L. A. M. Nem só carne nem sem carne: psicanálise e ciências cognitivas. PHYSIS - Rev. Saúde Coletiva, Rio de Janeiro, v. 10, n. 1, p. 121-142, 2000.

BASTOS, L. A. M. Psicanálise e cultura: a rosa solitária e o homem solidário. TRIEB - Revista da Sociedade Brasileira de Psicanálise do Rio de Janeiro, v. 8, p. 151-162, 1999.

BERG, M. Racionaliting medical work: decision-support tecnhiques and medical practices: Cambridge: MIT Press, 1997.

CANGUILHEM, G. O normal e o patológico. Rio de Janeiro: ForenseUniversitária, 1978.

CASTIEL, L. D. A medida do possível... saúde, risco e tecnobiociências. Rio de Janeiro: Contracapa, 1999.

CASTORIADIS, C. A Instituição imaginária da sociedade. Rio de Janeiro: Paz e Terra, 1995.

COELHO, M. T. A. D.; ALMEIDA F ${ }^{\circ}$, N. Normal-patológico, saúde-doença: revisitando Canguilhem. PHYSIS - Rev. Saúde Coletiva, Rio de Janeiro, v. 9, n. 1, p. 13-36, 1999.

FONAGY, P. Newsletter IPA, v. 8, n. 2, p. 25, 1999.

FREUD, S. Estudios sobre la histeria (1893-1995) In: FREUD, S. Obras completas. Buenos Aires: Amorrrortu Eds., 1976. v.2.

La represión (1915) In: FREUD, S. Obras completas. Buenos Aires: Amorrrortu Eds., 1976. v.14. 
Lo inconsciente (1915).In: Sigmund Freud, Obras completas. Buenos Aires: Amorrrortu Eds; 1976. v.14.

Más allá del principio de placer (1920). In: FREUD, S. Obras completas. Buenos Aires: Amorrrortu Eds., 1976. v.14.

Proyecto de psicología (1895). In: FREUD, S. Obras completas. Buenos Aires: Amorrrortu Eds., 1976. v.1.

GOOD, B Comment faire de l'anthroplogie médicale? Médecine, racionalité et vécu. Paris: Institute Synthélabo, 1998.

LAPLANCHE, J. Curto Tratado do Inconsciente. J Psic SBPSP, v. 32, n. 58/59, p. 307-37, 1999.

LEMOS, C.T.G. Corpo e linguagem. In: JUNQUEIRA F $F^{o}$ L.C.U. (Org). Corpo-mente: uma fronteira móvel. São Paulo: Casa do Psicólogo, 1996. NOVAES, H.M.D. Incorporação e utilização de tecnologias: a boa prática médica. Médico. HC-FMUSP, v. 2, n. 7, p. 19-21, 1999.

PALLY, R. How the brain actively constructs perceptions. Int. J. PsychoAnal., v. 78, p. 1.021-30, 1997.

ROUDINESCO, E. Por que a psicanálise? Rio de Janeiro: Jorge Zahar, 2000.

SAYD, J. D. Novos paradigmas e saúde: notas de leitura. Physis - Rev. Saúde Coletiva, Rio de Janeiro, v. 9, n. 1, p. 113-121, 1999.

SEARLE, J.R. O mistério da consciência. São Paulo: Paz e Terra, 1998. SERPA JR., O. D. Clínica e evidência: em que se baseiam as nossas decisões? Cadernos IPUB, Rio de Janeiro, v. 15, p. 61-79, 1999.

SHERWIN, B. B. Estrogen effects on cognition in menopausal women. Neurology, 48 (Suppl. 7), p. S21-S26, 1997.

URREGO, J. Newsletter IPA, v. 8, n. 2, p. 32, 1999.

\section{NOTA}

1 Professora de Psicologia Médica do Departamento de Psiquiatria da UFRJ. Doutora em Saúde Coletiva pelo IMS/UERJ. Membro efetivo da SBPRJ. E-mail: lianabastos@alternex.com.br 


\section{ABSTRACT}

\section{Evidence-Based Psychoanalysis?}

Based on the discussion concerning the efficacy of psychoanalysis, the author considers the need to engage in dialogue with the neurosciences and psychopharmacology. She indicates how the criterion of efficacy, as defined by evidence-based medicine, erases the dimension of the narrative and consequently that of subjectivity. She presents as a vignette an emergency case at the Clementino Fraga Filho University Hospital in Rio de Janeiro, illustrating the possibility of maintaining psychoanalytic listening in psychiatric treatment.

Keywords: Subjectivity; narrative; efficacy.

Recebido em: 22/05/2002.

Aprovado em: 25/10/2002. 